\title{
Differences in upper gastrointestinal neoplasm detection rates based on inspection time and esophagogastroduodenoscopy training
}

\section{(ㄷ)(우)}

\author{
Authors \\ Shoichi Yoshimizu, Toshiaki Hirasawa, Yusuke Horiuchi, Masami Omae, Akiyoshi Ishiyama, Toshiyuki Yoshio, \\ Tomohiro Tsuchida, Junko Fujisaki
}

Institution

Division of Gastroenterology, Cancer Institute Hospital, Tokyo, Japan

submitted 14.3 .2018

accepted after revision 25.6.2018

\author{
Bibliography \\ DOI https://doi.org/10.1055/a-0655-7382 | \\ Endoscopy International Open 2018; 06: E1190-E1197 \\ (c) Georg Thieme Verlag KG Stuttgart · New York \\ ISSN 2364-3722
}

Corresponding author

Shoichi Yoshimizu, Department of Gastroenterology, Cancer Institute Hospital, Japanese Foundation for Cancer Research, 3-8-31 Ariake, Koto-ku, Tokyo 135-8550, Japan Fax: +81-3-3520-0141

shoichi.yoshimizu@jfcr.or.jp

\section{ABSTRACT}

Background and study aims Esophagogastroduodenoscopy (EGD) has utility in early detection of upper gastrointestinal (UGI) neoplasms. However, previous studies report shorter inspection times and inexperienced endoscopists contribute to overlooking gastric neoplasms. We investigated neoplasm detection rates according to inspection time and extent of EGD training.
Patients and methods In this retrospective observational study, we reviewed routine EGDs for 3,925 consecutive cases between October 2014 and March 2015. We divided the endoscopists into three groups based on median inspection time during EGD without undergoing biopsy. Using cut-off median inspection times of 7 and 10 minutes, three, five, and eight endoscopists were classified into the fast, moderate, and slow groups, respectively. We compared detection rates according to inspection time and the extent of EGD training.

Results The median inspection time among all endoscopists was 9.3 minutes (range, $6.6-12.0 \mathrm{~min}$ ). The detection rate for UGI neoplasms was as follows: fast group, 3.6\%; moderate group, $3.3 \%$; and slow group, $3.1 \%(P=0.807)$. The median inspection time was significantly shorter among the intensive training $\geq 1$-year group than among the <1-year group (<1-year: median $6.3 \mathrm{~min}$; range 8.2 $13.9 \mathrm{~min}, \geq 1$-year: median $8.9 \mathrm{~min}$; range $6.4-11.4 \mathrm{~min}$, $P<0.001)$. The detection rate for UGI neoplasms was significantly higher among the intensive training $\geq 1$-year group than among the <1-year group (<1-year: $2.2 \%$; $\geq 1$-year: $3.7 \%, \mathrm{OR}=1.65,95 \% \mathrm{Cl}: 1.02-2.68, P=0.041)$.

Conclusions There was no association between inspection times and neoplasm detection rates. The quality of EGD, as measured by neoplasm detection rates, may be improved by $\geq 1$-year of intensive training.

\section{Introduction}

Gastric cancer is the fifth most common malignancy and the third leading cause of death from cancer worldwide [1,2]. Early detection is ideal for optimum patient survival, with esophagogastroduodenoscopy (EGD) being the most sensitive method for early detection [2,3]. Several studies have demonstrated the effectiveness of endoscopy screening for gastric cancer, with a $30 \%$ reduction in gastric cancer mortality as a result of cancer detection attributed to endoscopy screening [4-7].
Since then, in Korea and Japan, use of EGD has been allowed for gastric cancer screening in the national screening program $[8,9]$. Furthermore, EGD is also suggested to be effective for early detection of additional upper gastrointestinal (UGI) neoplasms, such as hypopharynx, esophageal, and duodenal tumors $[10,11]$. Although EGD is the standard procedure for diagnosing gastric cancer, inexperienced endoscopists tend to overlook gastric cancer due to subtle morphological changes in some early gastric cancer lesions, which are difficult to distinguish from background mucosa with atrophic change [12-14]. 
As a result, the false-negative rate for detecting gastric cancer with EGD is $4.6 \%$ to $25.8 \%$ [12, 15 - 19]. These findings indicate the importance of quality indicators (QI) for UGI neoplasm detection in EGD.

Several studies have reported quality indicator outcome measures in EGD [20-22]. A few previous studies found an association between inspection time during EGD and detection rates for UGI neoplasms. Results of those studies have shown that slower endoscopists detected a higher proportion of UGI neoplasms than faster endoscopists, suggesting that inspection time may be a useful quality indicator in EGD [23-25]. Conversely, other previous studies found that endoscopists require sufficient training and experience to detect gastric cancer properly [12-14]. We thus investigated inspection time and endoscopic training and experience to clarify quality improvement for UGI neoplasm detection in EGD.

\section{Patients and methods}

\section{Study design}

In this single-center, retrospective observational study, we reviewed routine EGDs for 5,091 consecutive cases at the Cancer Institute Hospital between October 2014 and March 2015. We selected this period because there was no change in the staff of endoscopists. We excluded 464 cases with EGD history within 6 months, 369 cases with endoscopic assessment by a clinician with less than 3 years of experience, 129 cases with endoscopic assessment by a clinician who performed fewer than 50 EGDs in this period, 67 cases of total gastrectomy surgery, 55 cases lacking information on stomach examination, 46 cases with residual food in the stomach, and 36 cases with ultrathin endoscopy examinations. Before undergoing EGD, all patients provided comprehensive written informed consent. The institutional review board of the Cancer Institute Hospital of the Japanese Foundation for Cancer Research approved this study (IRB no. 2016-1158) (> Fig. 1).

\section{Routine EGD}

Routine EGDs were performed from the hypopharynx to the horizontal part of the duodenum. Approximately 60 images were captured, including about 20 images taken in the hypopharynx and esophagus, and about 40 taken in the stomach and duodenum. Digital images were automatically saved in the endoscopic filing system. Two imaging modalities were alternated with conventional white-light imaging (C-WLI) and narrow-band imaging (NBI) when using the endoscope. NBI was used during withdrawal from the esophagus. The video processor was consistently set as follows. The structure enhancement function was set at the A5 or B8 level for C-WLI, with the color mode fixed at level 0 . All procedures were carried out using an endoscope manufactured by Olympus Corporation (GIF-H260 or GIF-H290Z, Olympus Medical Systems, Tokyo, Japan) and a standard endoscopic video system (EVIS LUCERA ELITE or EVIS LUCERA SPECTRUM, Olympus Medical Systems).

As a preliminary measure prior to endoscopy screening, pharyngeal anesthesia was administered using a lidocaine viscous solution. Almost all patients underwent endoscopy under
All routine EGD cases between October 2014 and March $2015(n=5,091)$

Excluded $(n=1,166)$ :

- Cases with EGD history within 6 months in our institute $(n=464)$

- Cases performed by endoscopists with experience less than three years $(n=369)$

- Cases performed by endoscopists with less than 50 EGDs in this period $(n=129)$

- Cases that underwent total gastrectomy surgery $(n=67)$

- Cases with lacking information on stomach examination $(n=55)$

- Cases with residual food in stomach $(n=46)$

- Cases using nasal endoscopy examinations $(n=36)$

Total cases included in this study $(n=3,925)$

- Fig. 1 Flowchart of routine EGD cases.

intravenous (IV) sedation, except for those with no preference for anesthesia. In accordance with the guidelines regarding sedation for gastroenterological endoscopy [26], midazolam $(2.0-5.0 \mathrm{mg})$ was administered IV, occasionally with pethidine hydrochloride $(35 \mathrm{mg})$ added for patients who were insufficiently sedated. When gastric or duodenal neoplasms were detected, a biopsy was performed after observation following NBI and dye spraying endoscopy with the application of indigo carmine. When esophageal neoplasms were detected, a biopsy was performed after observation following $\mathrm{NBI}$ and iodine spraying.

\section{Procedure and outcome parameters}

Inspection time was defined as the time from first image capture in the pharynx to scope removal. We divided endoscopists into three groups based on median inspection time during EGD without undergoing biopsy. The cut-off median inspection times were 7 and 10 minutes (min). The three groups were as follows: fast speed endoscopists (fast group: median inspection time, < $7 \mathrm{~min}$ ), moderate speed endoscopists (moderate group: median inspection time, $\geq 7 \mathrm{~min}$ and $<10 \mathrm{~min}$ ), and slow speed endoscopists (slow group: median inspection time, $\geq 10 \mathrm{~min}$ ).

The reason for the EGD was divided into screening and surveillance endoscopy. Screening endoscopy was defined as an inspection for cases without history of UGI neoplasms, such as examination of symptoms and a double cancer check before cancer treatment in another organ. Surveillance endoscopy was defined as periodic examination of cases with surgical and endoscopic treatment for UGI neoplasms. The Kimura-Takemoto classification is generally used for evaluating gastric mucosal atrophy [27]. We classified patients judged to have C-1 atrophic change or higher as atrophic gastritis regardless of presence of Helicobacter pylori. 
UGI neoplasms were defined as hypopharyngeal cancer, esophageal cancer, gastric adenoma/cancer, gastric carcinoid, duodenal adenoma/cancer, and duodenal carcinoid. Gastric neoplasms were defined as gastric adenoma, cancer, and carcinoid. We analyzed the characteristics, biopsy rate, and detection rate in the three groups. The detection rate was calculated as: Detection rate $=$ number of cases in which neoplasms were detected / number of routine EGDs. Furthermore, we compared the detection rate by duration of intensive training at the Cancer Institute Hospital.

\section{Intensive endoscopic training in the Cancer Institute Hospital}

The Cancer Institute Hospital is a famous high-volume center in Japan, which carries out 12,000 routine EGDs, approximately 450 gastric endoscopic submucosal dissections (ESD), and approximately 200 esophageal ESDs per year. Among the total 12,000 routine EGDs, each trainee can carry out more than 1000 routine EGDs. All patients planned for ESD and surgery undergo preoperative EGD in our hospital as well as a preoperative conference before treatment. Therefore, all trainees have opportunities to learn the endoscopic characteristics and features of approximately 550 surgeries and 450 ESD cases of gastric neoplasm, and approximately 100 surgeries and 200 ESD cases of esophageal neoplasm each year. Thus, intensive training in performing an EGD, endoscopic diagnosis, and treatment of UGI neoplasms are possible among the trainees.

\section{Statistical analysis}

Statistical analysis was carried out using SPSS software, version 24.0 (SPSS, Chicago, Illinois, United States). We compared categorical parameters using the chi-squared test and continuous parameters using the Mann-Whitney U-test and the KruskalWallis test. $P$ values $<0.05$ were determined to be statistically significant.

\section{Results}

\section{Characteristics of endoscopists}

All included routine EGDs were carried out by 16 endoscopists. Each endoscopist had carried out a minimum of 1000 EGDs and had $\geq 3$ years of experience before initiation of this study. Eleven were certified by the Japan Gastroenterological Endoscopy Society. A total of 1,931 of 3,925 EGDs (49.2\%) were normal without undergoing biopsy. Median inspection time during EGD without undergoing biopsy was 9.3 minutes (interquartile range, 6.6-12.0 min). Three endoscopists were classified into the fast group (median $6.3 \mathrm{~min}$; range, 5.0 - $7.5 \mathrm{~min}$ ), five into the moderate group (median $9.0 \mathrm{~min}$; range, $7.0-11.1 \mathrm{~min}$ ), and eight into the slow group (median 11.8 min; range, 9.0$14.7 \mathrm{~min}$ ), based on the aforementioned cut-off median inspection times. All endoscopists in the fast group were experts who had intensive training for $\geq 5$ years. Other endoscopist characteristics are shown in $>$ Table 1 .

\section{Characteristics of routine EGD between the fast- vs moderate- vs slow-speed endoscopist groups}

Among 5,091 consecutive routine EGDs, 3,925 EGDs satisfying the inclusion criteria were analyzed in this study. Characteristics of routine EGDs in three groups are shown in $>$ Table 2 . There was no significant difference in age and sex among the three groups. The interval between EGDs was $\leq 1.5$ years in approximately $75 \%$ of cases. Approximately half of EGDs were conducted for screening purposes, and half for surveillance purposes in each group. The prevalence of atrophic gastritis was $>70 \%$ in each group. Approximately $35 \%$ of cases had a history of gastric cancer; approximately $10 \%$ of cases had a history of esophageal cancer. No significant differences were identified among the three groups in terms of endoscopic system used. The total UGI biopsy rate showed no significant difference among the fast group (53\%), the moderate group (49\%), and the slow group (51\%) $(P=0.075)$. The proportion of endoscopists with $\geq 1$-year intensive training in the Fast group was significantly higher than those in the other two groups (fast group: $100 \%$; moderate group: $77 \%$; slow group: $63 \%, P<0.001)$.

\section{Neoplasm detection rate for fast vs moderate vs slow groups}

Neoplasm detection rates are shown in $>$ Table 3 . The neoplasm detection rate showed no significant difference among the three groups. The detection rate for UGI neoplasms was as follows: fast group, 3.6\%; moderate group, $3.3 \%$; slow group, $3.1 \%(P=0.807)$. The detection rate for gastric neoplasms was as follows: fast group, 2.9\%; moderate group, $2.1 \%$; slow group, $2.2 \%(P=0.336)$.

As shown in $>$ Table 4, 133 neoplasms (131 cases; two cases had both esophageal cancer and gastric cancer) (hypopharynx cancer: seven cases; esophageal cancer: 24 cases; early gastric cancer: 68 cases; gastric adenoma: 24 cases; gastric carcinoid: one case; duodenal cancer: two cases; duodenal adenoma: six cases; duodenal carcinoid: one case) were detected in this study.

\section{Characteristics of routine EGD between the intensive training $<1$-year vs $\geq 1$-year groups}

Characteristics of routine EGDs are shown in $>$ Table 5. Five endoscopists were classified as having intensive training $<1$ year and 11 as having $\geq 1$ year, based on duration of intensive training at the Cancer Institute Hospital. The proportion of history of gastric cancer among the Intensive training<1-year group was significantly higher than that among the Intensive training $\geq 1$-year group (<1-year group: $40 \%$; $\geq 1$-year: $34 \%$; $P=$ $0.001)$. The median inspection times among the Intensive training $\geq 1$-year group were significantly shorter than that among the Intensive training<1-year group (<1-year group: median $6.3 \mathrm{~min}$; range 8.2 -13.9 min; $\geq 1$-year group: median $8.9 \mathrm{~min}$; range $6.4-11.4 \mathrm{~min}, P<0.001)$. The other parameters were not different between the two groups. 
- Table 1 Number of EGDs, training period, inspection time, and neoplasm detection rates by endoscopists.

\begin{tabular}{|c|c|c|c|c|c|c|c|c|c|}
\hline & & & & & & & & Detectior & te $(\%)$ \\
\hline & $\begin{array}{l}\text { Endos- } \\
\text { copist }\end{array}$ & $\begin{array}{l}\text { Certi- } \\
\text { fied }^{1}\end{array}$ & $\begin{array}{l}\text { Intensive } \\
\text { training } \\
\text { (year) }\end{array}$ & $\begin{array}{l}\text { Median time } \\
\text { of group } \\
(\mathrm{min})^{2}\end{array}$ & $\begin{array}{l}\text { Median time } \\
\text { of endoscopist } \\
(\mathrm{min})^{2}\end{array}$ & $\begin{array}{l}\text { No. } \\
\text { of } \\
\text { EGDs }\end{array}$ & $\begin{array}{l}\text { Biopsy } \\
\text { rate } \\
(\%)\end{array}$ & $\begin{array}{l}\text { UGI } \\
\text { neo- } \\
\text { plasms }\end{array}$ & $\begin{array}{l}\text { Gastric } \\
\text { neo- } \\
\text { plasms }\end{array}$ \\
\hline Fast-speed & A & + & $\geq 5$ & 6.3 & $6.2(5.1-7.2)$ & 406 & 42.6 & $11(2.7)$ & $9(2.2)$ \\
\hline group & B & + & $\geq 5$ & $1.0-$ & $6.3(4.7-7.9)$ & 435 & 55.6 & $16(3.7)$ & $12(2.8)$ \\
\hline$(n=1,052)$ & C & + & $\geq 5$ & & $6.9(4.7-9.1)$ & 211 & 69.2 & $11(5.2)$ & $10(4.7)$ \\
\hline Moderate- & D & + & 0.5 & & $7.9(5.3-10.5)$ & 132 & 43.9 & $3(2.3)$ & $0(0)$ \\
\hline $\begin{array}{l}\text { speed } \\
\text { endoscopists }\end{array}$ & $\mathrm{E}$ & - & 1 & & $8.4(6.9-10.0)$ & 587 & 52.0 & $22(3.7)$ & $15(2.6)$ \\
\hline $\begin{array}{l}\text { group } \\
(n=1,314)\end{array}$ & $\mathrm{F}$ & + & 2 & $\begin{array}{l}9.0 \\
(7.1-11.0)\end{array}$ & $9.3(6.7-12.0)$ & 185 & 42.2 & $5(2.7)$ & $4(2.2)$ \\
\hline & G & - & 0.5 & & $9.8(7.9-11.7)$ & 173 & 46.2 & $5(2.9)$ & $3(1.7)$ \\
\hline & $\mathrm{H}$ & + & $\geq 5$ & & $9.9(8.3-11.7)$ & 236 & 49.6 & $9(3.8)$ & $5(2.1)$ \\
\hline Slow-speed & I & + & $\geq 5$ & 11.8 & $10.1(7.5-12.8)$ & 170 & 35.9 & $6(3.5)$ & $5(2.9)$ \\
\hline $\begin{array}{l}\text { endoscopists } \\
\text { group }\end{array}$ & J & + & 2 & $(9.0-14.7)$ & $10.9(9.1-12.7)$ & 169 & 51.5 & $7(4.1)$ & $5(3.0)$ \\
\hline$(n=1,559)$ & K & + & $\geq 5$ & & $11.2(8.8-13.6)$ & 148 & 55.4 & $6(4.1)$ & $3(2.0)$ \\
\hline & $\mathrm{L}$ & - & 0.5 & & $11.7(8.2-15.1)$ & 278 & 53.6 & $5(1.8)$ & $4(1.4)$ \\
\hline & M & + & 1.5 & & $11.7(9.5-13.9)$ & 200 & 56.5 & $11(5.5)$ & $8(4.0)$ \\
\hline & N & - & 0.5 & & $12.3(9.3-14.9)$ & 160 & 70.0 & $4(2.5)$ & $4(2.5)$ \\
\hline & $\mathrm{O}$ & - & 0.5 & & $12.7(8.8-15.2)$ & 148 & 45.9 & $3(2.0)$ & $2(1.4)$ \\
\hline & $\mathrm{P}$ & + & 1 & & $13.3(10.0-16.5)$ & 287 & 42.9 & $7(2.4)$ & $4(1.4)$ \\
\hline Total or Median & 16 & 11 & & & $9.3(6.6-12.0)$ & 3925 & 50.8 & $131(3.3)$ & $93(2.4)$ \\
\hline
\end{tabular}

\section{Comparison of neoplasm detection rates between Intensive training < 1-year vs $\geq 1$-year group}

As shown in $>$ Table 6, detection rates for UGI neoplasms and gastric neoplasms in the Intensive training $\geq 1$-year group were significantly higher than that in the Intensive training < 1-year group (UGI neoplasms; <1-year: 2.2\%; $\geq 1$-year: $3.7 \%$, odds ratio $=1.65,95 \% \mathrm{Cl}: 1.02-2.68, P=0.041$; gastric neoplasms; <1-year: $1.5 \%$; $\geq 1$-year: $2.6 \%$, odds ratio $=1.83$, $95 \% \mathrm{Cl}: 1.01$ 3.30, $P=0.045)$.

\section{Discussion}

Early detection of UGI neoplasms is ideal for ensuring optimum patient survival. Furthermore, EGD is the most sensitive method for early detection. Although quality control of EGD is necessary in early detection of UGI neoplasms, few studies have assessed quality indicators in EGD. Several quality indicators have been identified in colonoscopy for colorectal cancer screening, such as adenoma detection rate (ADR), inspection time, and surveillance intervals [28-30]. Measuring the ADR of individual colonoscopists is a priority in the quality improve- ment process for colonoscopy [30]; the same is also true in EGD. However, the detection rate can be affected by prevalence, so simply comparing the detection rate in each hospital is not a good method. Prevalence also varies widely based on geographic location, race, and socioeconomic status [31]. Especially, the predominant risk factor for gastric cancer is Helicobacter pylori infection, and major risk factors for esophageal squamous cell cancer include consumption of alcohol and smoking. Thus, in the current study, we compared the detection rate in the same hospital, as there is no associated bias with prevalence.

Previous studies have shown that slow-speed endoscopists had a higher detection rate for UGI neoplasms than fas- speed endoscopists [23-25]. In this study, the neoplasm detection rates showed no significant difference among the fast, moderate, and slow groups. There was no association between inspection time and neoplasm detection rates. However, median inspection time in EGD without undergoing biopsy was 9.3 minutes, which was longer than that in previous reports. Moreover, median inspection time in the fast group was 6.3 minutes, and even the fastest endoscopist had a median inspection time $\geq 6$ minutes. Meanwhile, previous reports have indicated that in- 
- Table 2 Characteristics of routine EGDs between the fast- vs moderate- vs slow-speed endoscopist groups.

\begin{tabular}{|c|c|c|c|c|}
\hline & $\begin{array}{l}\text { Fast-speed } \\
\text { endoscopists group } \\
(n=1,052)\end{array}$ & $\begin{array}{l}\text { Moderate-speed } \\
\text { endoscopists group } \\
(n=1,314)\end{array}$ & $\begin{array}{l}\text { Slow-speed } \\
\text { endoscopists group } \\
(n=1,559)\end{array}$ & $P$ value \\
\hline Age, median (range) & $67(18-92)$ & $67(20-93)$ & $68(18-92)$ & 0.321 \\
\hline Sex (\%) male/female & $649(62) / 403(38)$ & $833(63) / 481$ (37) & $649(62) / 403(38)$ & 0.460 \\
\hline Interval between EGDs (\%) & & & & 0.215 \\
\hline . $\leq 1.5$ years & $827(79)$ & $1010(77)$ & $1230(79)$ & \\
\hline - >1.5 years & $162(15)$ & $195(15)$ & $226(14)$ & \\
\hline - Unknown & $63(6)$ & $109(8)$ & $103(7)$ & \\
\hline \multicolumn{5}{|l|}{ Purpose of EGD (\%) } \\
\hline - Screening/surveillance & $530(50) / 522(50)$ & $600(46) / 714(54)$ & $762(49) / 797(51)$ & 0.107 \\
\hline \multicolumn{5}{|l|}{ Gastric mucosal atrophy (\%) } \\
\hline - Atrophy/non-atrophy & $733(70) / 319(30)$ & $970(74) / 344(26)$ & $1113(71) / 446(29)$ & 0.078 \\
\hline \multicolumn{5}{|l|}{ Past history of gastric cancer (\%) } \\
\hline - With/without & $352(33) / 700(67)$ & $471(36) / 843(64)$ & $569(36) / 990(64)$ & 0.265 \\
\hline \multicolumn{5}{|l|}{ Past history of esophageal cancer (\%) } \\
\hline - With/without & $123(12) / 929(88)$ & $135(10) / 1179(90)$ & $194(12) / 1365(88)$ & 0.188 \\
\hline \multicolumn{5}{|l|}{ Endoscope model (\%) } \\
\hline . GIF-H260/GIF-H290Z & $487(46) / 565(54)$ & $571(43) / 743(57)$ & $741(47) / 818(53)$ & 0.087 \\
\hline \multicolumn{5}{|l|}{ Light source model (\%) } \\
\hline - SPECTRUM/ELITE & $487(46) / 565(54)$ & $571(43) / 743(57)$ & $718(46) / 841(54)$ & 0.275 \\
\hline UGI biopsy cases (\%) Done / Not done & $561(53) / 491(47)$ & $639(49) / 675(51)$ & $794(51) / 765(49)$ & 0.075 \\
\hline \multicolumn{5}{|l|}{ Intensive training (\%) } \\
\hline$<1$-year $/ \geq 1$-year & $0(0) / 1052(100)$ & $306(23) / 1008(77)$ & $585(37) / 974(63)$ & $<0.001$ \\
\hline
\end{tabular}

- Table 3 Comparison of neoplasm detection rates between the fast-vs moderate- vs slow-speed endoscopist groups.

\begin{tabular}{|l|l|l|l|}
\hline & $\begin{array}{l}\text { Fast-speed } \\
\text { endoscopists group } \\
(\mathbf{n = 1 , 0 5 2 )}\end{array}$ & $\begin{array}{l}\text { Moderate-speed } \\
\text { endoscopists group } \\
(\mathbf{n = 1 , 3 1 4 )}\end{array}$ & $\begin{array}{l}\text { Slow-speed } \\
\text { endoscopists group } \\
(\mathbf{n = 1 , 5 5 9 )}\end{array}$ \\
\hline Detection rate for UGI neoplasms (\%) & $38(3.6)$ & $44(3.3)$ & $49(3.1)$ \\
\hline Detection rate for gastric neoplasms (\%) & $31(2.9)$ & $27(2.1)$ & $35(2.2)$ \\
\hline UGI, upper gastrointestinal neoplasms & & & 0.807 \\
\hline
\end{tabular}

spection time is a quality indicator for EGD; Kawamura et al. [23] (fast-speed endoscopist group mean inspection time, 4.4 min), Teh et al. [24] (fast-speed endoscopist group mean inspection time, $5.5 \mathrm{~min}$ ), and Park et al. [25] (fast-speed endoscopist group mean inspection time, 2.38 minutes, defined as the time from when the endoscope reached the duodenum to the time it was withdrawn) have suggested that EGD be carried out with a shorter inspection time than that seen in this study. Thus, according to the cut-off inspection times shown in previous reports, the endoscopists classified as fast in this study are actually moderate or slow. This may indicate that the fast endoscopists in this study (median inspection time $\geq 6 \mathrm{~min}$ ) had a suitable inspection time to decrease the likelihood of overlooking UGI neoplasms. However, all endoscopists in the fast group in this study were expert endoscopists who had sufficient experience (intensive training at our hospital for $\geq 5$ years).

In terms of endoscopic training and experience, previous studies reported that inexperienced endoscopists tend to overlook gastric cancer [12-14]. This means that endoscopists re- 
- Table 4 Characteristics of the all detected neoplasms in the fast- vs moderate- vs Slow-speed endoscopist groups.

\begin{tabular}{|c|c|c|c|c|}
\hline & $\begin{array}{l}\text { Fast-speed } \\
\text { endoscopists group } \\
(n=1,052)\end{array}$ & $\begin{array}{l}\text { Moderate-speed } \\
\text { endoscopists group } \\
(n=1,314)\end{array}$ & $\begin{array}{l}\text { Slow-speed } \\
\text { endoscopists group } \\
(n=1,559)\end{array}$ & $\begin{array}{l}\text { Total } \\
(n=3,925)\end{array}$ \\
\hline UGI neoplasms (\%) & $38(3.6)^{1}$ & $44(3.3)$ & $49(3.1)$ & $131(3.3)$ \\
\hline Hypopharynx cancer (\%) & $0(0)$ & $4(0.30)$ & $3(0.19)$ & $7(0.18)$ \\
\hline Esophageal cancer (\%) & $8(0.76)$ & $9(0.67)$ & $7(0.45)$ & $24(0.61)$ \\
\hline Gastric neoplasm (\%) & $31(2.9)$ & $27(2.1)$ & $35(2.2)$ & $93(2.4)$ \\
\hline Gastric cancer (\%) & $24(2.3)$ & $20(1.5)$ & $24(1.5)$ & $68(1.7)$ \\
\hline Gastric adenoma (\%) & $7(0.67)$ & $6(0.46)$ & $11(0.71)$ & $24(0.61)$ \\
\hline Gastric carcinoid (\%) & $0(0)$ & $1(0.08)$ & $0(0)$ & $1(0.03)$ \\
\hline Duodenal cancer (\%) & $0(0)$ & $1(0.08)$ & $1(0.06)$ & $2(0.05)$ \\
\hline Duodenal adenoma (\%) & $1(0.10)$ & $2(0.15)$ & $3(0.19)$ & $6(0.15)$ \\
\hline Duodenal carcinoid (\%) & $0(0)$ & $1(0.08)$ & $0(0)$ & $1(0.03)$ \\
\hline
\end{tabular}

- Table 5 Characteristics of routine EGD between the Intensive training < 1-year vs $\geq 1$-year groups.

\begin{tabular}{|c|c|c|c|}
\hline & $\begin{array}{l}\text { Intensive training }<1 \text {-year group } \\
(\mathrm{n}=891)\end{array}$ & $\begin{array}{l}\text { Intensive training } \geq 1 \text {-year group } \\
(\mathrm{n}=3,034)\end{array}$ & $P$ value \\
\hline Age, median (range) & $67(21-88)$ & $67(18-93)$ & 0.521 \\
\hline Sex (\%)Male/female & $542(61) / 349(39)$ & $1894(62) / 1140(38)$ & 0.388 \\
\hline Interval between EGDs (\%) & & & 0.606 \\
\hline . $\leq 1.5$ years & $699(79)$ & $2368(78)$ & \\
\hline . >1.5 years & $135(15)$ & $447(15)$ & \\
\hline - Unknown & $56(6)$ & $219(7)$ & \\
\hline \multicolumn{4}{|l|}{ Purpose of EGD (\%) } \\
\hline - Screening/Surveillance & $405(46) / 486(54)$ & $1479(49) / 1555(51)$ & 0.084 \\
\hline \multicolumn{4}{|l|}{ Gastric mucosal atrophy (\%) } \\
\hline - Atrophy/non-atrophy & $647(73) / 244(27)$ & $2169(72) / 865(28)$ & 0.512 \\
\hline \multicolumn{4}{|l|}{ Past history of gastric cancer (\%) } \\
\hline - With/without & $359(40) / 532(60)$ & $1033(34) / 2001(66)$ & 0.001 \\
\hline \multicolumn{4}{|l|}{ Past history of esophageal cancer (\%) } \\
\hline - With/without & $91(10) / 800(90)$ & $361(12) / 2673(88)$ & 0.166 \\
\hline \multicolumn{4}{|l|}{ Endoscope model (\%) } \\
\hline . GIF-H260/GIF-H290Z & $432(49) / 459(51)$ & $1367(45) / 1667(55)$ & 0.071 \\
\hline \multicolumn{4}{|l|}{ Light source model (\%) } \\
\hline " SPECTRUM/ELITE & $425(48) / 466(52)$ & $1351(44) / 1683(56)$ & 0.095 \\
\hline UGI biopsy cases (\%) Done/Not done & $467(52) / 424(48)$ & $1527(50) / 1507(50)$ & 0.274 \\
\hline Inspection time, min, median (range ${ }^{1}$ ) & $11.0(8.2-13.9)$ & $8.9(6.4-11.4)$ & $<0.001$ \\
\hline
\end{tabular}


- Table 6 Comparison of UGI neoplasm detection rates between the Intensive training < 1 -year vs $\geq 1$-year groups.

\begin{tabular}{|l|c|c|}
\hline & Detection rate (\%) & Odds ratios $\mathbf{( 9 5 \%} \mathbf{C l})$ \\
\hline Detection for UGI neoplasms (\%) & & \\
\hline Intensive training < 1-year group & $20(2.2)$ & 1.0 (Reference) \\
\hline Intensive training $\geq 1$-year group & $111(3.7)$ & $1.65(1.02-2.68)$ \\
\hline Detection for gastric neoplasms (\%) & & 1.0 (Reference) \\
\hline Intensive training<1-year group & $13(1.5)$ & $1.83(1.01-3.30)$ \\
\hline Intensive training $\geq 1$-year group & $80(2.6)$ & \\
\hline UGI, upper gastrointestinal & & 0.041 \\
\hline
\end{tabular}

quire sufficient training to detect gastric cancer properly. In this study, although all trainees had experienced more than 1000 EGDs in another hospital, the detection rate for UGI and gastric neoplasms by endoscopists with $\geq 1$-year intensive training was significantly higher than that by endoscopists with $<1$ year intensive training. In addition, endoscopists with $\geq 1$-year intensive training have significantly shorter inspection times than endoscopists with $<1$-year intensive training. Thus, intensive training for $\geq 1$ year made it possible to detect more neoplasms within a shorter examination time. This indicates that the quality of EGD, as measured by neoplasm detection rates, may be improved by $\geq 1$-year intensive training. Each trainee at our hospital can carry out approximately 1000 EGDs each year. Moreover, each trainee has opportunities to learn from the endoscopic findings of approximately 1000 cases of gastric neoplasm, and 300 cases of esophageal cancer each year. To improve the detection rate, it is also necessary to gain experience identifying many tumor characteristics and features in addition to technical training in EGD.

In this study, the biopsy rate (50.8\%) was slightly high, which may be because we tend to perform many biopsies, as it is a cancer specialty hospital visited by many patients with a high cancer risk. Approximately $35 \%$ of cases showed gastric cancer history, approximately $10 \%$ of cases showed esophageal cancer history, and more than $70 \%$ of cases showed atrophic gastritis, which has a high risk of progressing to gastric cancer. In these patients, we usually perform more careful examinations to avoid overlooking small lesions. Accordingly, nearly all neoplasms found in this study were determined to be early-stage cancer.

The current study had some limitations. First, it was a nonrandomized, retrospective, single-center study. Second, this study included a small number of cases. Third, a patient-selection bias might have been present. To reduce selection bias, we included all consecutive EGDs performed in a period where the staff of endoscopists was unchanged. Further, we planned the study after the case selection period. Therefore, we believe information bias from the endoscopists is relatively low. However, future prospective study with randomization in multiple centers is necessary to validate our findings.

\section{Conclusion}

In conclusion, there was no association between inspection time and UGI neoplasm detection rates. Endoscopists with $\geq 1$ year intensive training have significantly higher UGI neoplasm detection rates than endoscopists with $<1$ year of intensive training, although inspection times were significantly shorter. Accordingly, our results demonstrated that the quality of EGD, as measured by UGI neoplasm detection rates, may be improved by intensive training.

\section{Competing interests}

None

References

[1] Ferlay J, Soerjomataram I, Dikshit R et al. Cancer incidence and mortality worldwide: sources, methods and major patterns in GLOBOCAN 2012. Int J Can 2015; 135: E359- 386

[2] Sano T, Coit DG, Kim HH et al. Proposal of a new stage grouping of gastric cancer for TNM classification: International Gastric Cancer Association staging project. Gastric Cancer 2017; 20: 217- 225

[3] Katai H, Ishikawa T, Akazawa K et al. Five-year survival analysis of surgically resected gastric cancer cases in Japan: a retrospective analysis of more than 100,000 patients from the nationwide registry of the Japanese Gastric Cancer Association (2001-2007). Gastric Cancer 2018; $21: 144-154$

[4] Hamashima C, Shabana M, Okada K et al. Mortality reduction from gastric cancer by endoscopic and radiographic screening. Cancer Sci 2015; 106: $1744-1749$

[5] Hamashima C, Ogoshi K, Narisawa R et al. Impact of endoscopic screening on mortality reduction from gastric cancer. World J Gastroenterol 2015; 21: $2460-2466$

[6] Matsumoto S, Yoshida Y. Efficacy of endoscopic screening in an isolated island: a case-control study. Indian J Gastroenterol 2014; 33 : $46-49$

[7] Hamashima C, Ogoshi K, Okamoto M et al. A community-based, casecontrol study evaluating mortality reduction from gastric cancer by endoscopic screening in Japan. PLoS ONE 2013; 8: E79088

[8] Hamashima C, Shibuya D, Yamazaki $\mathrm{H}$ et al. The Japanese guidelines for gastric cancer screening. Jpn J Clin Oncol 2008; 38: 259-267 
[9] Lee KS, Oh DK, Han MA et al. Gastric cancer screening in Korea: report on the national cancer screening program in 2008. Cancer Res Treat 2011; 43: 83-88

[10] Muto M, Minashi K, Yano T et al. Early detection of superficial squamous cell carcinoma in the head and neck region and esophagus by narrow band imaging: a multicenter randomized controlled trial. J Clin Oncol 2010; 28: 1566-1572

[11] Goda K, Kikuchi D, Yamamoto Y et al. Endoscopic diagnosis of superficial non-ampullary duodenal epithelial tumors in Japan: multicenter case series. Dig Endosc 2014; 26: 23 -29

[12] Hosokawa O, Hattori M, Douden $\mathrm{K}$ et al. Difference in accuracy between gastroscopy and colonoscopy for detection of cancer. Hepatogastroenterology 2007; 54: 442-444

[13] Yamazato T, Oyama T, Yoshida T et al. Two years' intensive training in endoscopic diagnosis facilitates detection of early gastric cancer. Intern Med 2012; 51: 1461 - 1465

[14] Zhang Q, Chen ZY, Chen CD et al. Training in early gastric cancer diagnosis improves the detection rate of early gastric cancer: an observational study in China. Medicine 2015; 94: E384

[15] Melo AR, Soares M, Libanio D et al. Missing rate for gastric cancer during upper gastrointestinal endoscopy: a systematic review and meta-analysis. Eur J Gastroenterol Hepatol 2016; 28: 1041 - 1049

[16] Raftopoulos SC, Segarajasingam DS, Burke V et al. A cohort study of missed and new cancers after esophagogastroduodenoscopy. Am J Gastroenterol 2010; 105: $1292-1297$

[17] Yalamarthi S, Witherspoon P, McCole D et al. Missed diagnoses in patients with upper gastrointestinal cancers. Endoscopy 2004; 36: $874-879$

[18] Vradelis S, Marchnard N, Warren BF et al. Quality control in upper gastrointestinal endoscopy: detection rates of gastric cancer in Oxford 2005-2008. Postgrad Med J 2011; 87: 335-339

[19] Menon S, Trudgill N. How commonly is upper gastrointestinal cancer missed at endoscopy? A 276 meta-analysis Endosc Int Open 2014; 2: E46-E50
[20] Bisschops R, Areia M, Coron E et al. Performance measures for upper gastrointestinal endoscopy: a European Society of Gastrointestinal Endoscopy (ESGE) Quality Improvement Initiative. Endoscopy 2016; 48: $843-864$

[21] East JE, Vleugels JL, Roelandt $P$ et al. Advanced endoscopic imaging: European Society of Gastrointestinal Endoscopy (ESGE) Technology Review. Endoscopy 2016; 48: 1029 - 1045

[22] Rutter MD, Senore C, Bisschops R et al. The European Society of Gastrointestinal Endoscopy Quality Improvement Initiative: developing performance measures. Endoscopy 2016; 48: $81-89$

[23] Kawamura T, Wada H, Sakiyama $\mathrm{N}$ et al. Inspection time as a quality indicator of screening upper gastrointestinal endoscopy for asymptomatic examinees. Dig Endosc 2017; 29: 569 - 575

[24] Teh JL, Tan JR, Lau LJ et al. Longer inspection time improves detection of gastric cancer during diagnostic upper gastrointestinal endoscopy. Clin Gastroenterol Hepatol 2015; 13: 480-487

[25] Park JM, Huo SM, Lee HH et al. Longer observation time increases proportion of neoplasms detected by esophagogastroduodenoscopy. Gastroenterology 2017; 153: 460-469

[26] Obara K, Haruma K, Irisawa A et al. Guidelines for sedation in gastroenterological endoscopy. Dig Endosc 2015; 24: 435 -449

[27] Kimura K, Takemoto T. An endoscopic recognition of the atrophic border and its significance in chronic gastritis. Endoscopy 1969; 1: $87-97$

[28] Fayad NF, Kahi C]. Quality measures for colonoscopy: a critical evaluation. Clin. Gastroenterol Hepatol 2014; 12: $1973-1980$

[29] Lee TJ, Rutter MD, Blanks RG et al. Colonoscopy quality measures: experience from the NHS Bowel Cancer Screening Programme. Gut 2012; 61: 1050 - 1057

[30] Rex DK, Petrini JL, Baron TH et al. Quality indicators for colonoscopy. Am J Gastroenterol 2006; 101: 873-885

[31] Crew KD, Neugut Al. Epidemiology of gastric cancer. World J Gastroenterol 2006; 12: 354-362 